Instructions for authors, subscriptions and further details:

http://brac.hipatiapress.com

\title{
Quiasmo Metodológico: El Arte como Fuente de Experiencia
}

\section{Oriol Alonso ${ }^{1}$}

1) Facultad de Psicología, Universidad de Barcelona. Facultad de Turismo, Escuela Universitària Formatic Barcelona (España)

Date of publication: October $3^{\text {rd }}, 2016$

Edition period: October 2016 - February 2017

To cite this article: Alonso, O. (2016). Quiasmo metodológico: el arte como fuente de experiencia. Barcelona, Research, Art, Creation, 4(3), 248-271. doi: 10.17583/brac.2016.1936

To link this article: http://dx.doi.org/10.17583/brac.2016.1936

\section{PLEASE SCROLL DOWN FOR ARTICLE}

The terms and conditions of use, except where otherwise noted, are related to the Open Journal System and to Creative Commons Attribution License (CCBY). The indication must be expressly stated when necessary. 
BRAC - Barcelona Research Art Creation. Vol. 4 No. 3, October 2016, pp. 248-271

\section{Methodogical Chiasmus: Art as a Source of Experience}

Oriol Alonso

Faculty of Psychology, University of Barcelona. Faculty of Turism, Formatic Barcelona University School (Spain)

(Received: 9 February 2016; Accepted: 26 September 2016; Published: 3 October 2016)

\section{Abstract}

This research proposes to indicate the need of multiplicity of methodologies in the moment to approach at human experience. Any methodological imperialism (scientific, social, humanist...) of subjectivity it's condemned to the failure since it will be unable to be able to include the totality of the ontological wealth of the human experience. For this reason, it will be observed like, the art, it can be raised in a diaphanous example of methodology that, close to the rest of disciplines, offers us the possible tools to be able to work with the experience.

Keywords: Experience, science, neuroscience, art, writing, music. 
BRAC - Barcelona Research Art Creation. Vol. 4 No. 3, October 2016, pp. 248-271

\section{Quiasmo Metodológico: El Arte como Fuente de Experiencia}

Oriol Alonso

Facultad de Psicología, Universidad de Barcelona. Facultad de Turismo, Escuela Universitària Formatic Barcelona (España)

(Recibido: 9 Febrero 2016; Aceptado: 26 Septiembre 2016; Publicado: 3 Octubre 2016)

\section{Resumen}

El objetivo de este breve estudio estriba en señalar la necesidad de apostar por una multiplicidad de metodologías en el momento de abordar la experiencia del sujeto. Cualquier imperialismo metodológico (científico, social, humanista...) sobre la subjetividad se halla condenado al fracaso, puesto que será incapaz de abarcar toda la riqueza ontológica de la experiencia humana. Por ese motivo, y en particular, se observará cómo el arte puede erigirse en un diáfano ejemplo de metodología que, en perpetuo diálogo con el resto de disciplinas, nos pueda ofrecer elementos conceptuales y metodológicos para acometer el estudio de la experiencia en toda su plenitud.

Palabras clave: Experiencia, ciencia, neurociencia, arte, escritura, música

2016 Hipatia Press

ISSN: 2015-8992

DOI: $10.17583 /$ brac. 2016.1936

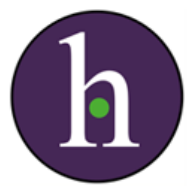






os hallamos en un contexto histórico en el que cualquier aproximación a la experiencia del sujeto debe regirse por los exclusivos parámetros de lo cuantitativo. De modo que nos encontramos en la encrucijada de considerar a la subjetividad como una instancia que puede medirse, controlarse y regularse. Sin embargo este fenómeno no es exclusivo de nuestra época. El imperialismo metodológico de la ciencia ha existido desde que los primeros fisicoi analizasen empíricamente la realidad con el afán de exhumar sus principios constitutivos (arjé) ${ }^{1}$. A su vez, el rechazo de esta invasión científica de lo humano también se ha alzado desde los albores de la civilización, con Sócrates, la sofística o Platón.

Visto que no es un tema novedoso, debemos observar de qué manera, en la contemporaneidad, se establece, de nuevo, este reino despótico de la ciencia para con la experiencia, tal y como afirman autores como Damasio, Dennett o Kandel. Y, en esta ocasión, este poder se realiza bajo la batuta de las neurociencias. La peculiaridad del discurso neurocientífico es que, más allá de su materialismo, experimentalismo, anhelo de imponer leyes y demás características propias de cualquier paradigma que se califique de científico, su novedad se ubica en que ha conseguido ocupar un espacio que, hasta ahora, lo ocupaban las ciencias del espíritu ${ }^{2}$. La neurociencia pretende ahondar experimentalmente en la experiencia del sujeto para comprenderla, tipificarla $\mathrm{y}$, finalmente, establecer las leyes que regulen su funcionamiento (Damasio, 1994).

Sin embargo, al proceder de esta manera, caerá en las aporías propias del cientificismo en el momento en que pretende descubrir los patrones normativos que determinan al ser humano. La explicación de la ciencia se mueve a través de experimentos, conceptos y leyes causales, entre otras instancias. El problema es que la experiencia es poliédrica, rica, dinámica, en constante devenir, temporal, dúctil... y, en consecuencia, se escabulle de la rigidez de las categorías y de la estabilidad de lo nomológico (Feyerabend, 1975). Asimismo, la metodología experimental está repleta de suposiciones y prejuicios que provocan desajustes en su pretendida objetividad y universalidad (Feyerabend, 1984; Popper, 1963). Más aún si cabe, este prurito de traducir lo mental a lo cuantitativo se convierte en algo más que cuestionable ${ }^{3}$ (Davidson, 1980; Quine, 1995) al tratarse de dos órdenes inconmensurables ${ }^{4}$. 
Así pues, la ciencia, en general, y las neurociencias, en particular, se ven sometidas a toda una serie de dificultades que imposibilitan ese imperialismo metodológico que tanto desean. Su acercamiento a la experiencia está repleto de problemas insalvables que invalidan su intento de establecerse como la única disciplina viable para acercarse a la esencia de la experiencia. De ahí que sea necesario que entre en un diálogo con otros espacios, o saberes, con el fin de obtener los máximos puntos de vista posibles en torno a la naturaleza de la experiencia. Es esencial que la ciencia, en primer lugar, acepte que no es el único campo que se ocupa fielmente de la experiencia del sujeto y, en segundo término, que se digne a entrar en un diálogo y colaboración con otros discursos o que abordan el experienciar del ser humano desde otras perspectivas.

$\mathrm{Y}$ es en este punto donde el arte puede tener una mayor relevancia en esta encrucijada ante la experiencia humana. La experiencia artística constituye una de las más fundamentales aproximaciones a la experiencia humana. Por ejemplo, la historia de la pintura puede ser leída como la historia de la búsqueda de la experiencia plena del ser humano. Movimientos tan dispares como el realismo, impresionismo, abstraccionismo o surrealismo son intentos de destilar la experiencia con el fin de alcanzar su mayor grado de pureza.

Para un epistemólogo como Feyerabend, el arte es una experiencia capaz de resolver problemas que la ciencia es incapaz de solucionar. Es decir,

los artistas han resuelto problemas que todavía confunden a serios pensadores objetivos (por ejemplo, cómo captar la subjetividad de una persona de una forma que la haga accesible a otros), y que sus medios de presentación son mucho más ricos, mucho más adaptables y mucho más realistas que los estériles esquemas que uno puede encontrar en las ciencias sociales (Feyerabend, 1984, p. 71).

La experiencia artística tiene la habilidad de aportar matices y aspectos de la experiencia humana que la rigidez del pensamiento científico jamás será capaz de vislumbrar (Feyerabend, 1984). Una de las razones de esta premisa radica en que, para Feyerabend, el estatuto de la experiencia estética será eminentemente práctica. El arte nos perturba, nos moviliza, apunta a la acción, a la praxis, y, de ahí que,

las ideas que usamos al actuar han superado el test de la práctica; han sido modificadas por emociones, deseo, sueños de quienes participan 
en la acción (...), lo que significa que han absorbido una gran parte de la subjetividad de los agentes. Esta es, por tanto, la razón por la que no tengo nada que decir sobre problemas políticos, éticos, estéticos, científicos, etc.: una discusión abstracta de las vidas de gentes que no conozco, y cuya situación no me es familiar, no es sino una pérdida de tiempo" (Feyerabend, 1984, p. 79).

El arte, en tanto que acción, es vida, experiencia y experimentación (Argullol, $2000 ; 2006 ; 2010)$, espacio dinámico donde se materializa una experiencia de orden diferente a la que se establece en el resto de saberes. Es una experiencia viva, desnuda, carnal, donde los conceptos y las leyes dejan de ser válidas y el sujeto se sumerge en un abismo que lo modificará por completo (Argullol, 2010). El verdadero arte es conmoción, catarsis, pero no en un sentido aristotélico de purificación, sino de transformación, de metamorfosis de la subjetividad. La auténtica experiencia artística desestabiliza los cimientos del individuo, desestructura su pensamiento, su logos, para convertirlo en un individuo completamente diferente al que era antes de dicha experiencia.

\section{La Escritura como Experiencia: Blanchot y la Experiencia Original}

Esta necesidad del arte de convertirse en experiencia o de conducir a la experiencia originaria puede apreciarse en diferentes propuestas artísticas. Por ejemplo, y dentro del campo de la literatura, el conjunto de obras que configuran las tragedias de Esquilo, Sófocles o Eurípides deben ser consideradas como retratos que pretenden ahondar en la experiencia buscando capturar los fulgores de autenticidad de la misma. Lo mismo podría decirse de las obras de la literatura y del pensamiento místico de Eckhart, Silesius (Vega, 2011), Böhme, Tauler, San Juan de la Cruz o Santa Teresa de Jesús; de la Bildungsroman de los hemanos Schlegel, Novalis, Hölderlin, Goethe, Keats, Leopardi, von Kleist (Argullol, 1984); o bien de las tentativas contemporáneas vinculadas con la poética del silencio o con la desestructuración formal de la generación beat, entre los innumerables ejemplos que se podrían hallar a lo largo de la historia de la cultura occidental.

En la mayoría de estas tentativas, la escritura se define como una búsqueda de la experiencia auténtica, donde la palabra intenta conmocionar, evocar, 
provocar y, finalmente, alcanzar un espacio de experiencia originario. Estas propuestas rechazan todo tipo de autoritarismo, sea del autor o del lector, y transitan a través de las fronteras formales, temáticas o estilísticas con la voluntad de palpar algún aspecto prístino del experienciar del sujeto.

El estatuto ontológico de la obra es, según palabras de Blanchot, solitaria y esencial, incomunicable e inconclusa (Blanchot, 1955). Expresado en otros términos, la obra implica una soledad esencial en la que el trabajo que se plasma en ella jamás puede ser reducido a una mercancía acabada cuyo sentido último puede ser captado, con más o menos problemas, por el lector, y que es difundido, consciente o inconscientemente, por el autor. La obra, según Blanchot, "sigue siendo lo interminable" (Blanchot, 1955, p. 17). y asienta a su creador

a un trabajo ilusorio. Al final la obra lo ignora y vuelve a cerrarse sobre su ausencia en la afirmación impersonal, anónima, de que es, y nada más. Esto se traduce señalando que el artista, que sólo termina su obra en el momento de morir, nunca llega a conocerla (Blanchot, 1955, p. 17).

Es decir, la obra es un espacio esencial en el que quedan atrapados todos los agentes implicados en la experiencia de la lectura. El autor, nunca podrá leer su obra ${ }^{5}$ puesto que se le escapan absolutamente todos los sentidos que esta posee en el momento en que se encarna sobre el papel. El escritor pierde la capacidad de enmarcar su obra como una voz de su yo. Más aún si cabe, debe renunciar a su yo en el instante en que afronta la escritura.

Por su lado, la palabra rompe con su uso cotidiano, el lenguaje es desalojado de su significación corriente. En la escritura, se retira "el lenguaje del curso del mundo" (Blanchot, 1955, p. 20).se elimina el poder del mundo que se transluce en la palabra para erigirse en portadora del silencio ${ }^{6}$, en transmisora de una nada que al mismo tiempo es ser ${ }^{7}$.

El tiempo de la obra, a su vez, implica la ausencia de tiempo. Su temporalidad destroza las coordenadas del tiempo físico ${ }^{8}$ y se convierte en un "tiempo donde nada comienza, donde la iniciativa no es posible, donde antes que la afirmación ya hay el regreso de la afirmación” (Blanchot, 1955, p. 23). Es una temporalidad no dialéctica, donde se anuncia lo ausente, en la que 
lo presente no presenta nada, se representa, pertenece desde ahora en adelante y en todo tiempo al regreso. Esto no es, pero vuelve, viene como ya y siempre pasado, de modo que no lo conozco, pero lo reconozco, y este reconocimiento arruina en mí el poder de conocer, el derecho de percibir, de lo inasible hace también lo indesprendible, lo inaccesible que no puedo dejar de esperar, lo que no puedo tomar sino retomar, y no dejar nunca (Blanchot, 1955, p. 24).

Finalmente, el lector no es un ente que recibe, con mayor o menor dosis de pasividad, la obra, y que, finalizada la lectura, se encargaría de dotar de un sentido determinado y unívoco al texto. Para Blanchot, el lector, el receptor de la obra, es alguien que se mueve a través de la mirada y de lógica de la fascinación. Dicho en otras palabras, la mirada fascinada es un

poder que la neutraliza, que no la suspende ni la detiene, sino que, al contrario, la impide terminar nunca, le corta todo comienzo, hace de ella un neutro resplandor extraviado que no se apaga, que no ilumina, el círculo, cerrado sobre sí, de la mirada (Blanchot, 1955, p. 26).

De esta manera, el lector se encuentra en la misma tesitura que el autor, enfrascado en el seno de una diáspora perpetua de sentido que él jamás constituye ni constituirá. El espectador fascinado es alguien que, más allá de toda incapacidad de instituir sentido, se encuentra prisionero de una distancia inalcanzable, de una profundidad ilimitada que es el universo de la obra. Es

la mirada de la soledad, la mirada de lo incesante y de lo interminable donde la ceguera todavía es visión, visión que ya no es posibilidad de ver sino imposibilidad de no ver, la imposibilidad que se hace ver, que persevera -siempre y siempre- en una visión que no terminó, mirada muerta, mirada convertida en el fantasma de una visión eterna (Blanchot, 1955, p. 26).

Sin embargo, esta mirada fascinada que capta lo que se halla oculto en la obra, ni mucho menos debe ser entendida como una capacidad del sujeto de apresar el sentido del texto. Como se ha destacado antes, el lector ni otorga sentido pero tampoco excava mediante su lectura la crisálida de palabras que 
recubren un presunto sentido. En particular,

alguien está fascinado, y hablando con exactitud, no ve eso que ve, pero eso lo toca en una proximidad inmediata, se apodera de él y lo acapara, aunque lo deje absolutamente a distancia. La fascinación está fundamentalmente ligada a la presencia neutra, impersonal, el Uno indeterminado, el inmenso Alguien sin rostro. Es la relación que mantiene la mirada -relación neutra e impersonal- con la profundidad sin mirada y sin contorno, la ausencia que se ve porque ciega (Blanchot, 1955, p. 27).

Hay una relación de posesión, entendida ésta más desde una perspectiva místico-mágico-religiosa que de pertenencia voluntaria del sujeto. El universo que se establece con la obra es un microcosmos donde la experiencia originaria es crucial. Se lleva a cabo un vínculo con la realidad esencial del individuo, se desgajan las cadenas del mundo a medida que se adentra en el espacio generado por la obra. Dicho espacio puede ser designado de muchas maneras, según Blanchot -el Afuera, la noche, intemperie, soledad esencial....- pero lo que está claro es que la lectura abre al individuo a un mundo donde la realidad cotidiana abandona su sentido y lo sitúa en unas coordenadas esenciales, en un marco originario en el que se puede acceder a un horizonte prístino de su experiencia.

\section{Schopenhauer y la Música como Manifestación de la Esencia}

Esta capacidad del arte de configurar un espacio originario, una vía de acceso a la experiencia más prístina del individuo, no se circunscribe únicamente al mundo de la literatura, sino que también podemos hallarlo en el campo de la música. La experiencia musical es, según varias propuestas, uno de los medios más eficaces para conducirnos a un horizonte originario de la experiencia. Y en esta tematización de la música como guía hacia lo originario, las reflexiones de Schopenhauer son fundamentales. Fue uno de los autores que apostó más fuerte en la modernidad por la relevancia ontológica de la música como instancia que puede captar la esencia de lo real.

En términos generales, Schopenhauer es uno de los críticos más exacerbados del afán cientificista en su intento de abordar la totalidad de la realidad. Para él, la esencia del mundo, el núcleo de sentido de la realidad, es la voluntad 
(Wille), en contraposición de la representación (Vorstellung), que constituye el mundo tal y como captan nuestros sentidos y razona nuestro entendimiento ${ }^{9}$. Ahora bien, para Schopenhauer el mundo de la representación es un mundo, expresado en términos kantianos, fenoménico y, en consecuencia, somero, superficial o, si se quiere, inauténtico. La esencia de la realidad, la voluntad, es aquello hacia lo que se debe dirigir el verdadero conocimiento.

Para tipificar este conocimiento, debemos desembarazarnos de todo lo que implica la lógica de la representación: la voluntad de vivir, la fenomenalidad del mundo, el yo y la satisfacción de sus necesidades, el principuim rationis... Es decir, deberemos alejarnos de todas las realidades que nos anclan al mundo como representación y dirigirnos a la objetividad de la voluntad pura.

De esta manera, por ejemplo, el yo debe desprenderse de su individualidad, cristalizada por todo aquello que constituyen sus intereses vitales ${ }^{10}$, mientras que el mundo, cuando se ultrapasa su dimensión de representación, desaparece en tanto que serie fenoménica. Dicho en otras palabras, a partir de la elevación hacia la voluntad (Schopenhauer, 1819) el correlato sujeto-objeto dejará de tener validez ${ }^{11}$. En este punto, el yo es un ojo claro, diáfano, carente de refracciones al eliminar todo instinto e interés vital y, por ende, al cercenar su voluntad de vivir. Por su lado, el mundo aparece de una forma esencial como voluntad objetivada a través de los fenómenos.

Sin embargo, para describir la modalidad de conocimiento superior que capte esta alianza esencial, Schopenhauer se remitirá a la Kritik der Urteiskraftl kantiana y a sus análisis sobre los juicios estéticos. Recordemos que para Kant los juicios estéticos atienden a la realidad de la cosa sin reclamar la presencia del aparato categorial del entendimiento (Kant, 1790). De esta manera, cuando el sujeto es capaz de observar el mundo sin la interferencia de los esquemas intelectuales, según Kant, se apreciarán las cosas tal y como son. Esta mirada sin óbices epistemológicos es lo que Kant designa como experiencia estética. No obstante, la operatividad de los juicios estéticos depende primordialmente de que el sujeto se desligue de todo tipo de interés ${ }^{12}$ y sólo aquel que ha eliminado cualquier actitud interesada, estará en condiciones de tener la pura contemplación de las estructuras de la facticidad.

Pues bien, Schopenhauer toma todas estas consideraciones y las sitúa en el terreno del conocimiento propio de la voluntad ${ }^{13}$, llegando a afirmar que el arte se erige en el órganon por antonomasia del conocimiento ${ }^{14}$. El artista, según la propuesta schopenhaueriana, no ofrece al público ni un producto epistemológico ni un mandato ético, sino que plasma una realidad que no se circunscribe a la vida. Mediante el arte nos ubicamos en un contexto 
contemplativo que deja al eterno presente de la voluntad su perpetua manifestación. Por consiguiente, en lo artístico alcanzaremos el auténtico conocimiento de lo real al desprenderse del mundo, con su irrealidad y sus imposiciones, y alojarnos en la voluntad.

Ahora bien no todas las disciplinas tienen la misma relevancia para llevar a cabo este cometido esencial. Por ese motivo, Schopenhauer establecerá una jerarquía estética, que, a su vez, corresponderá con los grados de manifestación de la voluntad. Dependiendo del grado de apertura que posibilita a la voluntad, habrá unas artes que se situarán por encima del resto. Concretamente, la jerarquía que realiza Schopenhauer es, siguiendo un orden de menor a mayor grado de relevancia: arquitectura, jardinería, pintura y escultura naturalistas, artes humanas (pintura histórica, arte poético) (Schopenhauer, 1819).

En esta clasificación, Schopenhauer excluye un arte que, aunque sea de facto plenamente coherente con ella, se halla al margen: la música. La razón de esta exclusión radica en que "en ella no conocemos la copia, la reproducción de alguna idea del ser del mundo: pero es un arte tan grande y magnífico, actúa tan poderosamente en lo más íntimo del hombre" (Schopenhauer, 2004, p. 311). Con ella sucede algo especial que la desvincula por completo del resto de disciplinas: no expresa, como las otras, la manifestación de la voluntad en ideas. No obstante, al ser un arte debe ser una forma de representación relacionada necesariamente con la voluntad. Así pues, sólo puede representar una cosa: la voluntad misma. En la música, consecuentemente, no se objetivan arquetipos de la voluntad sino el propio proceso, como dinamismo generador, en el que la voluntad se objetiva en ideas. Mostrará el proceso dinámico del que brota, a la sazón de la unidad de la voluntad, la pluralidad de ideas y formas fenoménicas.

Cada arte hace referencia a las diversas formas de objetivación, es decir, al fenómeno de la representación y, por ende, a las sombras de la auténtica realidad. De modo que, mientras que el resto de las disciplinas expresan idealizaciones de la voluntad, la música muestra la pulsión originaria de la que se cristalizarán dichas idealizaciones. Es de esta manera puesto que la música opera con sonidos, con procesos, con, tal y como ulteriormente observaremos en John Cage, duraciones. Un sonido engendra a otro por proceso de génesis. A su vez, la combinación musical permite generar formas comparables a vivencias y experiencias del sujeto.

Más aún, a diferencia del arte dramático, de la tragedia en especial, en la música no hay palabras, es decir, no hay condiciones para efectuar el 
juicio moral que se efectúa en las artes dramáticas. Hay el puro proceso de manifestación y transformación de formas. Es una universalidad que no se encuentra circunscrita en la encrucijada de los idiomas concretos de cada artista y de cada oyente. De ahí que se excluya a la ópera ya que desvirtúa el momento prístino del proceso al presentar la palabra. La ópera es un género híbrido que introduce en su dinamismo la lógica del habla ${ }^{15} \mathrm{y}$, por ello, se aleja de la pureza ontológica que exige el movimiento originario de la voluntad.

Así pues, la música goza de una importancia fundamental para Schopenhauer en tanto que se adentra en el abismo esencial de la realidad y, en consecuencia, en el hontanar de la experiencia del sujeto. Dinamita el armazón conceptual, egoísta, causal, cientificista que constituye el mundo como representación y sitúa al sujeto ante su verdadera experiencia, que jamás será suya en términos egocéntricos, la voluntad.

\section{John Cage: Ante el Abismo de las Duraciones}

El arte debe ser experiencia. Si pretende tener algún tipo de validez, debe convertirse en una instancia vital y apostar por adentrarse en el fulgor de la experiencia y dejarse engullir por su vitalidad. Blanchot defendía una escritura en la que las coordenadas tradicionales de autor-receptor se desmoronaban ya que, esencialmente hablando, la obra es un espacio originario de experiencia. Con Schopenhauer, el arte, en general, y la música, en particular, se convertía en un proceso en el que se manifestaba la esencia de la realidad y, consecuentemente, la verdadera experiencia. En la propuesta de John Cage hay una apuesta por una radicalización de la experiencia artística hasta alcanzar el paroxismo. La visión que tiene Cage del arte y, en especial, de la música -su arte-, se enlaza con la necesidad de ser experimentada hasta sus raíces más profundas. La música es experiencia y, como tal, se liga estructuralmente a aquel que la escucha. Lo musical consiste en una

organización de sonidos, silencios, y duraciones que construyen edificios audibles. La escucha de la música se efectúa en un recorrido que habita una casa, un laberinto, un jardín sonoro. Componer y escuchar música es a veces edificar arquitecturas audibles (Pardo Salgado, 1999, p. 9).

Es un mosaico de diferentes instancias entre las que destaca, por encima del 
resto, su carácter de duración. Es una cadencia, movimiento, algo fluido que circula para conmocionar a todos los agentes implicados en su circulación. Hasta aquí, la coincidencia con Schopenhauer es plena. No obstante, Cage se empieza a alejar en el instante en que rechaza la utilización de la música para fines epistemológicos o metodológicos. La obra musical es un continuum de duraciones pero jamás, según Cage, podrán encuadrarse en unas instancias que persigan un método para exhumar o adueñarse de una realidad determinada. La música es duración y, en consecuencia, experiencia. Más allá de esto, no es nada.

Penetrando en los diferentes elementos que entran en juego en el proceso de composición de la pieza musical, Cage rechaza con virulencia la tradicional delimitación entre sonido, ruido y silencio. Esta diferenciación, en el momento de la elaboración musical, debe ser extirpada porque cualquier elemento es esencial para generar la obra. La perspectiva tradicional en la composición intentaba eliminar patrones como el silencio o el ruido, al ser elementos que no ligaban con la fluidez de la melodía, sin embargo para Cage son cruciales:

dondequiera que estemos, lo que oímos más frecuentemente es ruido. Cuando lo ignoramos, no molesta. Cuando lo escuchamos, lo encontramos fascinante. El sonido de un camión a cincuenta millas por hora. La estática entre emisoras. La lluvia. Queremos capturar y controlar estos sonidos, y usarlos no como efectos sonoros sino como instrumentos musicales (Cage, 1999. p. 51).

Tanto el ruido como el silencio son ingredientes vertebradores. En realidad, lo que subyace a este planteamiento es la eliminación de la estructura armónica tradicional. La razón de esta ruptura estriba en que la armonía tradicional funciona gracias a la complicidad de una concepción intelectualista de la obra. Expresado en otras palabras, Cage

abandona la casa del sonido y denuncia que el recorrido que se produce en esos edificios armónicos se guía por un oído intelectivo más que por un oído sensible. Cage piensa que los métodos actuales de enseñanza musical impartida en los Conservatorios muestran una actividad mental que crea relaciones pero olvida lo fundamental, el sonido (Pardo Salgado, 1999, p. 10). 
Con su concepción de la música, pretende superar las barreras que impone la armonía puesto que estas encubren una relación conceptual e intelectualista con la melodía que invalida toda experiencia estética auténtica y plena. Esta ruptura puede observarse diáfanamente en sus ejercicios de cadencia rota, donde

entrar en el bosque de la música será obligar al oído a pasar por lo inesperado, por los sonidos no reconocidos, simplemente a escuchar. El paseo por el bosque de la música requiere primero dirigir los pasos hacia la no intencionalidad para escuchar el sonido fuera de la medición que lo acota en una nota y establece su relación en el sistema (Pardo Salgado, 1999, p. 11).

Ahondar en el cosmos musical requiere el abandono del pensamiento conceptual para adentrarse en una imbricación entre elementos tan dispares como el sonido, ruido o silencio. De lo que se trata es de generar duraciones que no puedan acotarse a la mera relación sistemática de la notación musical de manera que se "crea un bosque que deja el oído a la intemperie. Un bosque de sonidos, silencios, ruidos y duraciones que hacen olvidar los contornos que distinguirán el sonido musical" (Pardo Salgado, 1999, p. 11).

Esta unión de elementos tan dispares, esta imbricación de realidades tan complejas, implica partir de la duración sin categorías, jerarquías o medidas preestablecidas. La génesis musical se ubica en la duración. Cualquier intento de fundar lo musical en otro parámetro no deja de ser un ademán más para salvaguardar la integridad del pensamiento conceptual, lo cual repercutirá en la consideración que se haga de la relación entre las notas. Cuando impera el intelectualismo y la categorización, el vínculo entre las notas es medible, cuantitativo y, por consiguiente, traducible a términos numéricos. Cuando sucede este hecho, la estructuración melódica pierde, según Cage, su carácter dinámico y se transforma en algo anquilosado, calculable y muerto. Por el contrario, la apuesta por la duración es una ruptura para con la medición inherente en la concepción tradicional de la música.

Para defender esta perspectiva, más allá de la cadencia rota, Cage se sumerge en un particular acto de artesanía creando el piano preparado:

reinventa el piano al manipularlo poniendo entre las cuerdas, a diferentes longitudes, materiales que modifiquen las cuatro características básicas del sonido: la duración, la amplitud, la frecuencia y el timbre. Así, el 
piano se metamorfosea convirtiéndose en un medio de generar nuevos sonidos y no en un fin al que acoplar los sonidos preexistentes (Pardo Salgado, 1999, p. 12).

El instrumento debe ser un dispositivo que genere duraciones, es decir, nuevas sonoridades que rompan con toda lógica preestablecida. El sonido no es algo preexistente que deba ajustarse a la materialidad del instrumento sino que, por el contrario, es lo instrumental quien debe transformarse en un medio en el que se gesten sonoridades novedosas. Existe una organización sistemática de la experiencia musical en el momento en que la entendemos como producción instrumental que mimetiza lo establecido en la notación de la partitura. En palabras del propio Cage,

si la palabra "música" se considera sagrada y reservada para los instrumentos de los siglos dieciocho y diecinueve, podemos sustituirla por otro término más significativo: organización del sonido (Cage, 1999. p. 52).

En toda esta nueva consideración de la música, el ruido y el silencio se erigen en elementos esenciales, tal y como se ha observado. En particular, el silencio es una realidad que obsesiona a Cage hasta el punto que necesita captarlo en la cámara anecoica de la Universidad de Harvard. Sin embargo, allí

en este cuarto silencioso escucha dos sonidos, uno agudo y otro grave. Son los sonidos de su sistema nervioso y de la circulación de su sangre. Esta experiencia le enseña que el silencio no existe como posibilidad de vivencia, que siempre hay sonido (Pardo Salgado, 1999, p. 13).

El silencio absoluto es una quimera, en realidad está preñado de sonoridad. No existe porque siempre se manifiesta como sonido o multiplicidad de sonidos. Así pues, el silencio, de forma análoga al ruido, se integrará en la temporalidad melódica, entendiéndola esta siempre como duración. Es bajo esta premisa como debe concebirse una de las obras más notorias de nuestro autor, 4'33, catalogada como su primera obra silenciosa. En realidad, la obra estaba compuesta de tres movimientos (Pardo Salgado, 1999), los célebres: 


\section{I \\ TACET \\ II \\ TACET \\ III \\ TACET}

Con ellos nuestro autor lo que pretendía es dejar al libre albedrío la composición, interpretación y escucha de la obra. Estos movimientos tenían la peculiaridad que debían ser entendidos de una forma absolutamente aleatoria, ya que "la partitura no es más una notación de signos abstractos susceptibles de ser traducidos sonoramente, sino un manual de instrumentos. Algo a hacer. Música igual a ACCIÓN" (Barber, 1985, p. 33)

La duración, 4'33, había surgido por puro azar. Sin embargo, el gran objetivo de Cage era que en ningún momento se fetichizase el azar. De modo que la "duración" será esta (4’33) o cualquier otra. La indeterminación, por la que Cage aboga, afectará también a la duración que estalla en manos del intérprete: él tendrá que "programar" el tiempo (Barber, 1985, p. 32)

Por lo que concierne a su ejecución, resaltar que es independiente la utilización de cualquier instrumento puesto que

el instrumento, sea piano o cualquier otro u otros, amén de fuente sonora, deviene "objeto": que está ahí ocupando un espacio; que se abre o se cierra, que se ensucia y se limpia. Mueble, y mueble viejo, en casa nueva. Fluxus sacará las consecuencias (Barber, 1985, p. 33).

Como se destacó en anterioridad, el medio objetivo que es el instrumento no deja de ser un espacio en el que fluyen y se gestan duraciones novedosas, donde el ser del sonido pasa a tener un estatuto ontológico de multiplicidad radical $\mathrm{y}$, debido a ello, "el sonido musical deja de ser la acotación de una vibración en una nota y pasa a vibrar por sí mismo, exhibiendo su multiplicidad" (Pardo Salgado, 1999, p. 14).

Merced a esta nueva dinámica, que encarna en sus primeras obras silenciosas, rompiendo con las categorías y el conceptualismo propios de la tradición, se hace trizas la tripartición clásica de compositor-intérprete-oyente. En este punto, coinciden las propuestas de Cage y Blanchot ${ }^{16}$, puesto que se elimina 
toda intencionalidad y subjetividad en la generación y recepción de la obra. Imbuido por el budismo, Cage aboga por eliminar el yo al ser una instancia represora que invalida cualquier experiencia artística. El ego, concretamente, es una instancia "que controla el gusto y la emoción. Gusto, memoria y emoción hacen del yo un muro que impide la percepción de la abundancia que oculta el edificio musical" (Pardo Salgado, 1999, p. 15).

El objetivo no es otro que restituir el verdadero sentido de la experiencia de la obra, en tanto y cuanto híbrido de duraciones. Para que se lleve a puerto será necesario acabar con la imagen del sujeto como ideal regulativo de la obra. El yo debe dejar de actuar como emisor de preceptos valorativos y normativos. Con ello, se rompe la dicotomía sujeto-objeto al existir una esencial imbricación de todas las instancias que participan en la experiencia de la música. Dicho en otros términos, el rechazo del dualismo se produce porque

la actividad del compositor y la del oyente se fundarán en la aceptación. La aceptación supone un nuevo modo de ser en el mundo. El rechazo de la teleología del arte y del hombre. Las consecuencias que se derivan de esta posición será la desaparición de la noción de obra y la indistinción entre arte y vida (Pardo Salgado, 1999, p. 15).

Ulteriormente, se recuperará esta tesis acerca de la indistinción entre vida $\mathrm{y}$ arte pero, por el momento, puede aseverarse la necesidad de eliminar el estatuto de obra, autoría, intérprete y espectador. Todos estos elementos se enmarcan en el seno de la misma experiencia. Son las piezas de la misma obra de teatro, con la peculiaridad de que no hay teatro ni representación: sólo experiencia.

Si no existe separación entre instancias no nos debe extrañar la temática de la nada-enmedio:

entre las cosas no hay nada, que nada las separa. La nada que está entre las cosas, los sonidos, sean como centros que irradian en todas las direcciones interpretándose. Este dejar que las cosas sean centros convierte también al hombre en una especie de centro vacío dispuesto a la aceptación (Pardo Salgado, 1999, p. 16).

No hay un único centro sonoro sino que hay muchos y todos ellos irradian una multiplicidad de duraciones que se penetran mutuamente. No existe el 
vacío entre las sonoridades puesto que la totalidad de la obra no es otra cosa que una amalgama de duraciones interpenetradas. La duración es la fuente, el resto de elementos son productos de la experiencia que genera esta unión de duraciones.

Si se asume con radicalidad la no intencionalidad, la primacía de la duración, y la ruptura con la concepción melódica tradicional, el azar gozará de una ingente relevancia. Tal y como puede apreciarse en piezas como Credo in us o Imaginary Landscape no. 4, el azar juega un papel esencial y, a partir de esta indeterminación estructural, Cage se adentra plenamente en la temática de la desaparición de la noción de obra. De esta manera, el azar posibilita a Cage

una disciplina sin intencionalidad y un acercamiento al modo en que opera la naturaleza. La antigua pared de la armonía pasa a ser ahora el equilibrio que aparece cuando se deja ser a las cosas y a los sonidos (Pardo Salgado, 1999, p. 18).

De lo que se trata es de eliminar cualquier ideal de representación para abogar por la apertura a una experiencia bruta, originaria, prístina, "no catalogada" (Pardo Salgado, 1999, p. 18). Hay que romper con el ideal mimético y adecuacionista y dejar que las cosas sean en sí mismas, y no imponerles ningún tipo de esquematismo o concepto. Y, al deshacernos de toda esa superestructura intelectualista, se tendrá como resultado la irrupción de la experiencia desnuda, carente de toda intencionalidad, teleología e intelectualismo. De modo que, la música será

afirmación de vida que no pretende hacer surgir el orden del caos, o lo determinado de lo indeterminado, sino simplemente que la gente se despierte al hecho de vivir liberándose de sus ideas y deseos. Se da un paso así a lo que él denomina una música ecológica, una música que permite habitar el mundo en su totalidad y no fragmentado por lo mental (Pardo Salgado, 1999, p. 18).

Esta afirmación de la vida es otra de las cuestiones que separa a Cage de las tesis anteriormente expuestas por Schopenhauer. Si para el filósofo alemán sólo la música es la condición de posibilidad de que el mundo, en tanto que juego dialéctico entre voluntad y representación, quede visibilizado en su mismisidad, el arte, no obstante, sigue siendo un acto que se transmite a un espectador determinado. En tanto que tal, lo estético se yergue en un espectáculo 
dentro del espectáculo que garantiza el movimiento de distanciación del mundo fenoménico. Gracias a ello, el sujeto se desvincula de sus intereses y puede acceder a la voluntad. De ahí la función terapéutica del arte puesto que, mientras dura la vivencia artística, el individuo se halla separado de su voluntad de vivir, es decir, de sus intereses egocéntricos. Pero esta situación será efímera. En concreto tendrá la vigencia de la pieza en cuestión y, una vez finalizada o interrumpida, emergerá nuevamente el dolor que conlleva el yo y sus intereses. En consecuencia, se trata más de un sedante para la existencia que de una verdadera ruptura ontológica.

Cage tomaría sin paliativos las tesis del juicio estético kantiano, pero reprocharía a Schopenhauer la imposibilidad de apreciar la obra más allá de la tripartición clásica de compositor-intérprete-oyente. Es esa demarcación la que provoca, en primer término, considerar el arte como un espectáculo (para que una realidad sea considerada como espectáculo debe haber una distinción entre agente-actor del mismo y paciente-receptor que lo reconoce en tanto que tal) así como un analgésico fugaz (al no haber tripartición, no existe la obra, sólo hay experiencia de duraciones que carecen de limitación temporal).

Esta indistinción de las instancias que tradicionalmente habían configurado la constelación musical (compositor, intérprete, oyente), así como la apertura a la experiencia plena que conduce la indeterminación, posibilitan una aproximación de la música al modo en que obra la naturaleza (Pardo Salgado, 2014). Al reinar el azar, la duración y la unión, la melodía actuará de la misma manera en que lo hace la naturaleza, será una entidad que carece de reglas y que opera desde la espontaneidad absoluta para hacer brotar experiencias en aquel que la experimenta. Este fenómeno se observa en el happening. En el espacio que genera el happening se da la multiplicidad de acontecimientos que carecen de centro. Es la experiencia de la confusión, de la unión y simultaneidad de todos los elementos que forman parte de la melodía.

Sin embargo, la consideración del happening y, en consecuencia, de la música como modalidad de experiencia esencial, requiere de la participación del oyente. La experiencia que provoca el arte no nos arroja a una pasividad radical en la que se recibe la duración de la melodía y se la experimenta pasivamente, sino que, por el contrario, requiere de la complicidad del receptor. El oído se encuentra en la encrucijada de duraciones, se ubica

a la intemperie escuchando el sonido que no cesa, escuchando a través del sonido y no de las ideas. Una escucha que surge del desconocimiento, de una atención a ese bosque que sólo remite al sonido mismo. La 
escucha de Cage es una acción, una percepción activa que convierte ese acto en una "permeabilidad generalizada" (Pardo Salgado, 1999, p. 21).

Esta permeabilidad depende de la aceptación, donde se lleva a cabo una activación inmediata de la escucha, es decir, "se trata de la aceptación de un acontecer sensible en el que no se puede distinguirse entre contenido de la experiencia y la experiencia como tal. El contenido no se contiene en ningún molde o modelo conceptual" (Pardo Salgado, 1999, p. 21).

El arte es modificación y producción de experiencia. La música altera la capacidad de experienciar del sujeto afectándolo irremediablemente en su relación con lo real. Como asevera Carmen Pardo, "el arte pasa a ser auto-expresión a ser auto-alteración” (Pardo Salgado, 1999, p. 21). Por ese motivo, la escucha debe desprenderse de cualquier juicio de valor ya que este deforma la experiencia. Como sucedía con los juicios estéticos kantianos, la regulación de las valoraciones impide la apertura necesaria para que se dé lugar la plena experiencia melódica. Se trata entonces de una escucha dirigida en la que no se experimenta la duración, sino que se destruye la experiencia al obstaculizarse, por un lado, la creación y la percepción, y, por el otro, al solidificarse y anquilosarse la capacidad de experienciar del individuo. Los valores, en realidad, no forman parte del sonido sino que son injertos dañinos que el sujeto introduce a la sonoridad para apropiársela. La valoración es afán de posesión y, por ende, aniquilación de la experiencia auténtica.

\section{Conclusiones}

Este estudio ha pretendido mostrar de qué manera el arte puede integrarse en un diálogo interdisciplinar en torno a la experiencia del ser humano. La experiencia artística, en tanto modo de experienciar, capta aspectos de la experiencia que se le escapan al discurso científico. En la actualidad, la ciencia busca exhumar los patrones que regulan la experiencia humana a través de la neurociencia. La experiencia originaria se le escabulle puesto que opera mediante conceptos, experimentos, patrones normativos que únicamente capturan la superficialidad de lo experienciable. Toda su riqueza ontológica, sin embargo, se le escapa de sus redes conceptuales y experimentales.

Por ello, la ciencia no debería estipularse como la metodología dominante para abordar la experiencia y debería entrar en un diálogo e interrelación con otros campos. Y es aquí donde el arte juega un papel crucial. Como se ha 
observado en los casos de Blanchot, Schopenhauer o Cage, el arte se sitúa en un horizonte donde palpa lo prístino de la experiencia. Para Blanchot, la escritura es la creación de un espacio de multiplicidad de sentido en el que lo que prima es la pureza de la experiencia de la obra. En ese universo, se desvanecen las categorías de autor, lector, tiempo, y se gesta un cosmos de soledad, de afuera, en el que lo esencial será la experiencia originaria.

La música, por su lado, en tanto que proceso, movimiento, interpenetración de duraciones, se erigirá en otro espacio artístico en el que se manifestará la esencia de lo real, según Schopenhauer, y la experiencia en su grado más elevado de pureza, según Cage. La música nos alejará del mundo como representación, de la realidad como fenómeno, y encarnará en su movimiento el ser de la experiencia y de lo real. A su vez, para Cage la música debe ser experiencia y, para ello, debería desprenderse de todas aquellas manifestaciones de la tradición que se guía por el racionalismo, lo conceptual y lo normativo. De lo que se trataría es de adentrarse en un actuar esencial, donde el individuo se encuentra aunado esencialmente con su realidad, y se hacen trizas las dicotomías clásicas de sujeto-objeto, autor-espectador... para zambullirse en la plenitud ontológica de la realidad y de la experiencia.

\section{Notas}

${ }^{1}$ La lectura arquetípica del paso del mito al logos se ubica en este punto en el que, gracias a las tentativas de los fisicoi se introduce el lenguaje de la ciencia en el mundo occidental. No obstante, la práctica protocientífica (experimentalismo, control de la realidad...) se inicia varios siglos atrás con los mesopotámicos, los egipcios...

${ }^{2}$ Si las Geisteswissenschaften se caracterizan por una apuesta por la comprensión, entendiéndola ésta como una facultad con un estatuto imaginativo que carece de fin y que siempre se halla relacionada, pero no adecuada plenamente, con el objetivo de comprensión (que no deja de ser otra que la vivencia del sujeto, la experiencia de la subjetividad); el discurso neurocientífico parece subvertir esa lógica al adueñarse del terreno experiencial. Para materializar dicha subversión, adopta los ropajes de la metodología de las ciencias del espíritu (su tarea pretende comprender los diferentes elementos que configuran la vivencia del individuo, entendiendo dicha tarea como un proceso que adolece de fin, que depende de la tradición en la que se inscribe su investigación...). Ahora bien, hablamos de ropaje y, como tal, es algo superficial debido a que en ningún momento el discurso neurocientífico pretende separarse de facto de la tradición científica, al buscar explicaciones causales y conexiones nomológicas entre 
el contenido de la experiencia y su correlato neuronal. Expresado en otros términos, el paradigma neurocientífico acaba cayendo en las redes del cientificismo más acuciante al pretender establecer leyes causales inviolables en su objeto de estudio. Con ello a lo que nos conducen sus consideraciones no es a otro lugar más lejano que las aporías propias de la ciencia en su intento de abordar la experiencia del sujeto.

${ }^{3}$ Quine (Quine, 1995) y Davidson (Davidson, 1980) otorgan la demoledora crítica de la inescrutabilidad de la referencia o, dicho en otros términos, de la intraducibilidad de los elementos mentales a términos materialistas. Son dos órdenes de lo real completamente inconmensurables y específicos y, por ese motivo, cualquier tentativa de reducir lo uno a lo otro, caerá en la aporía de traducir una realidad con la discursividad propia de la que ejerce el papel de traductor. En ningún caso será capaz de abordar la verdadera naturaleza de aquello traducido.

${ }^{4}$ Para ver un análisis exhaustivo de las dificultades de la neurociencia para captar todos los aspectos de la experiencia del sujeto, así como las aporías que alcanza véase: Alonso Cano, O (2015). Experiencia de la ausencia. Barcelona: Editorial Anthropos. ${ }^{5}$ Es esencial en este punto la temática de Blanchot del Noli me legere, en la que se transite la imposibilidad del autor de aproximarse a su obra. Dicho en otras palabras, la verdadera escritura deviene en una instancia que se le escapa por completo a su creador. Sin embargo, lejos de considerarse como algo negativo, o que conduzca a la frustración, es, en realidad, el único modo que tiene de relacionarse con ella. En el Noli me legere, el escritor es alejado de su obra y "lo obliga a regresar a ese "espacio" donde había entrado para transformarse en el sentido de lo que debía escribir. De modo que ahora vuelve a encontrarse como al comienzo de su tarea, encuentra la vecindad, la intimidad errante del afuera donde no puedo instalarme" (Blanchot, 1955, p. 18).

${ }^{6}$ De ahí que, "escribir es hacerse eco de lo que no puede dejar de hablar. Y por eso, para convertirse en eco, de alguna manera debe imponerse silencio" (Blanchot, 1955, p. 21).

7 “Escribir nunca consiste en perfeccionar el lenguaje corriente, en hacerlo más puro. Escribir comienza sólo cuando escribir es la aproximación a ese punto donde nada se revela, donde, en el seno de la disimulación, hablar aún no es sino la sombra de la palabra" (Blanchot, 1955, p. 42).

${ }^{8}$ En este punto, Blanchot se encamina hacia la propuesta de autores como Nietzsche, Bergson, Heidegger o Merleau-Ponty en las que se establece una dicotomía entre, por un lado, el tiempo que marca la física y el mundo de la cotidianidad, y, por el otro, el tiempo vivencial, experiencial, en el que lo esencial es la vivencia y no la cronología, donde no existe propiamente la tríada clásica pasado-presente-futuro sino que lo que prima es el fulgor de la experiencia, su dinamismo ontológico.

${ }^{9}$ Como es sabido, el mundo de la representación está fundamentado por el principio de razón suficiente (principium rationis, Satz vom Grunde) que nos conduce al hecho de que todo lo que podemos conocer acaba remitiendo a una determinada causa o razón de ser. Nuestra percepción de la realidad, bajo el sortilegio de la representación, 


\section{BRAC - Barcelona Research Art Creation, 4(3)}

se moverá bajo estos parámetros etimológicos. Evidentemente que este espacio será el propio de la disciplina científica y, por ese motivo, el conocimiento propio del mundo como representación será el científico.

${ }^{10}$ A este yo desinteresado, Schopenhauer lo designa de varias maneras, a lo largo de su obra. Antes de 1818, lo denominaba conciencia mejor, puesto que acarrea una forma de conocimiento superior al evadirnos de los intereses vitales. No obstante, acabará abandonando esta acuñación ya que la noción de conciencia (Bewusstsein) se encuentra vinculada estrechamente al idealismo y, por consiguiente, al ideal de la representación. Por ese motivo, Schopenhauer, ulteriormente, designará esta yoidad como sujeto puro de conocimiento, sujeto desprovisto de voluntad (entendida esta voluntad como voluntad de vivir $\mathrm{y}$, consecuentemente, como ligada irremediablemente a los intereses vitales), el ojo claro del mundo o el claro espejo de la esencia del mundo.

${ }^{11}$ Dejará de ser entendido en términos de fenómeno, es decir, de Erscheinung, de engaño.

${ }^{12}$ Para Kant, existen dos tipos de interés: el teórico y moral.

${ }^{13}$ No obstante, debe atenderse al hecho de que Kant no cesa de recordarnos que los juicios estéticos adolecen de conocimiento y únicamente son instancias que nos llevan al goce estético. Dicho en otros términos, no tienen validez epistemológica pero sí validez vivencial.

${ }^{14}$ Ya Schelling, en 1801, con su Sistema de idealismo transcendental expuso esta tesis. Cada producto artístico tiene la capacidad de conocer la objetividad y, por ende, se yergue en el paradigma filosófico central. No obstante, a diferencia de Schelling, el arte no nos da acceso a un Absoluto como unión de libertad y naturaleza, sino que ofrece una experiencia de la voluntad.

${ }^{15}$ No obstante, para Schopenhauer hay un autor que se escabulle de esta lógica perversa de la ópera: Rossini. En su ópera el texto es una instancia superflua y la primacía está en el devenir puro de la música.

${ }^{16}$ No únicamente coincide con Blanchot en este punto, sino también con autores como Nietzsche, Bergson, Merleau-Ponty o Deleuze, entre otros muchos. Para todos ellos, lo esencial se encuentra en despojarse de los límites que genera el yo que, con sus expectativas, deseos, frustraciones..., constriñen al sujeto encadenándolo en la inautenticidad e impidiéndole una experiencia plena. 


\section{Referencias}

Alonso Cano, O. (2015). Experiencia de la ausencia. Incapacidad cientifica para abordar lo prerreflexivo. Barcelona: Editorial Anthropos.

Argullol, R. (2000). Aventura. Una filosofia nómada, Barcelona: Nuevas Ediciones DeBolsillo, SL.

Argullol, R. (2006). Breviario de la aurora, Barcelona: Editorial Acantilado.

Argullol, R. (1984). El Héroe y el único. Madrid: Taurus Editorial. (Barcelona: Editorial Acantilado Quaderns Crema, S.A., 2008).

Argullol, R. (2010). Visión desde el fondo del mar, Barcelona: Editorial Acantilado.

Barber, L1. (1985). John Cage. Madrid: Círculo de Bellas Artes.

Blanchot, M. (1955). El espacio literario. Barcelona: Paidós. 1995.

Cage, J. (1937). El futuro de la música: credo. En Cage, J. Escritos al oído. Murcia: Colegio oficial de aparejadores y arquitectos técnicos de la región de Murcia. (Pardo Salgado, Carmen (Ed.).

Damasio, A. (1994). El error de Descartes: la emoción, la razón y el cerebro humano. Barcelona: Editorial Crítica. 2006.

Davidson, D. (1980). Filosofía de la psicología (Edición bilingüe).

Barcelona: Editorial Anthropos. Promat, S. Coop. Ltda. (1994).

Feyerabend. P.K. (1975). Against Method: Outline of an Anarchist Theory of Knowledge. London: New Left Science. Tercera edición 1980: Verso Books.

Feyerabend. P.K. (1984). Adiós a la razón. Madrid: Editorial Tecnos, S.A. Kant, I. (1790). Kritik der Urteilskraft. Berlin und Libau: Lagarde und Friederich. Consultada: Kritik der Urteilskraft Kant's gesammelte Schriften. (V), Berlin: Reimer. (1974).

Pardo Salgado, C. (1999). "Prólogo". En Cage, J. (1999). Escritos al oído. Murcia: Colegio oficial de aparejadores y arquitectos técnicos de la región de Murcia.

Pardo Salgado, C. (2014). La escucha oblicua. Una invitación a John Cage. Madrid: Editorial SextoPiso.

Popper, K. R. (1963). Conjeturas y Refutaciones. El desarrollo del conocimiento cientifico. Barcelona y Buenos Aires: Ediciones Paidós, Ibérica, S.A. y SAICF . 1983, a partir de la $4^{\text {a }}$ edición en inglés de 1972.

Quine, W.V. (1995). Selected logic papers. Enlarged edition. Cambridge: Harvard University Press. 
Schopenhauer, A. (1819). El mundo como voluntad y representación.

Madrid: Editorial Trotta, S.A. (2004).

Vega, A. (2011). Tres poetas del exceso. La hermenéutica imposible en Eckhart, Silesius y Celan. Barcelona: Fragmenta Editorial.

Oriol Alonso: Profesor en Universidad de Barcelona (Facultad de Psicología), UOC (Facultad de Psicología), Escuela Universitària Formatic Barcelona (Facultad de Turismo).

Contact Address: Passeig de Gràcia, 66, 08007, Barcelona.

E-mail address: oriolalonsocano@hotmail.com 